\title{
Tenderness and Color Stability of Beef Longissimus Thoracis and Semimembranosus Steaks From Carcasses With Varying Hot Carcass Weights
}

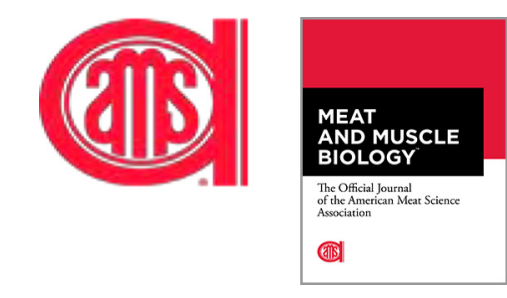

\author{
Michaella A. Fevold, Laura K. Grube, Wanda L. Keller, Kasey R. Maddock-Carlin, and \\ Robert J. Maddock*
}

Department of Animal Sciences, North Dakota State University, Fargo, ND 58105, USA

*Corresponding author. Email: robert.maddock@ndsu.edu (Robert J. Maddock)

\begin{abstract}
Our objectives were to determine how beef hot carcass weights relate to temperature and $\mathrm{pH}$ decline, WarnerBratzler shear force, and objective color of steaks from the longissimus thoracis and semimembranosus. Beef carcasses $(N=59)$ were selected at a commercial plant based on hot carcass weight and separated into either light- $(<363 \mathrm{~kg})$, medium- (364-407 kg), or heavy-weight ( $>408 \mathrm{~kg}$ ) groups. Temperature and $\mathrm{pH}$ in the longissimus thoracis and semimembranosus muscle were measured for $24 \mathrm{~h}$. After carcasses were chilled for approximately $24 \mathrm{~h}$, ribeye area, 12th rib backfat, kidney, pelvic, and heart fat percentage, marbling score, and USDA final yield grade were collected. Ribeye rolls (Institutional Meat Purchase Specification 112a) and inside rounds (Institutional Meat Purchase Specification 160a) were collected at the plant and transported to the North Dakota State University Meat Laboratory. Data were analyzed using the mixed procedure of SAS version 9.4 (SAS Institute Inc., Cary, NC) with carcass weight class as the fixed effect and day of collection as random. Longissimus thoracis muscle temperature of light-weight carcasses was lower at $4 \mathrm{~h}$ compared with heavy-weight carcasses $(P=0.02)$. Semimembranosus muscle temperature of light- and medium-weight carcasses was lower at $24 \mathrm{~h}$ compared with heavy-weight carcasses $(P<0.0001)$. There were no differences in $\mathrm{pH}$ decline $(P \geq 0.16)$ among carcass weight groups. There were no differences in fat thickness; kidney, pelvic, and heart fat percentage; or marbling score $(P \geq 0.12)$ among carcass groups. There were no differences in drip loss, cook loss, or Warner-Bratzler shear force in either longissimus thoracis or semimembranosus muscles $(P \geq 0.10)$ among carcass groups. Objective color measurements found that steaks from heavy-weight carcasses were redder than steaks from light-weight carcasses $(P \leq 0.02)$. Hot carcass weight group did not influence most meat quality attributes of steaks with the possible exception of color.
\end{abstract}

Key words: beef, steaks, tenderness, hot carcass weight, meat color Meat and Muscle Biology 5(1): 10, 1-7 (2021) doi:10.22175/mmb.11465

Submitted 18 June $2020 \quad$ Accepted 16 November 2020

\section{Introduction}

Tenderness is the main driver in beef consumer satisfaction and encourages return customers (Boleman et al., 1997). With this knowledge, research needs to be continually conducted in the United States in order to better understand what affects beef tenderness and how the beef industry can deliver consistent and satisfying products to consumers. However, it has been difficult to keep up with an ever-evolving beef industry. In 2015, the US produced more beef than it did in 1977, even with 13 million fewer cattle harvested (Maples et al., 2018). This increase can be attributed to many improved production methods, including improved genetics and nutrition. Increasing the efficiency of beef production in the US has resulted in live cattle and carcass weights increasing, with an increase in carcass weight of almost $45 \mathrm{~kg}$ in the past decade (Maples et al., 2018). In 2016, the National Beef Quality Audit reported that carcass weight and size was considered a top-six priority area, 
behind food safety, eating satisfaction, and lean fat and bone (NBQA, 2016). In addition to the increase in carcass weights, the industry has seen an increase in subcutaneous fat, as well as ribeye sizes (Igo et al., 2013).

There has been significant research over the years into how chilling rates and $\mathrm{pH}$ decline ultimately affects overall meat quality of beef. Chilling rates have been studied extensively, with "cold shortening" one of the most extensively studied phenomena. Cold shortening occurs when there is a very rapid decline in muscle temperature (to less than $14^{\circ} \mathrm{C}-19^{\circ} \mathrm{C}$ ) before the carcass has entered into the onset of rigor mortis (Locker and Hagyard, 1963). However, in order to better understand final beef quality, it is important to observe how the muscle temperature decline and muscle $\mathrm{pH}$ decline interact. In general, there are 2 main schools of thought about how the rate of muscle temperature and $\mathrm{pH}$ decline may affect overall meat quality of beef. The first is that, in order to maintain acceptable quality of beef, the muscle should be cooled to $7^{\circ} \mathrm{C}$ when the $\mathrm{pH}$ is around 5.6-5.8 (Hannula and Puolanne, 2004). However, there is also an idea of an "acceptable window" of muscle cooling and $\mathrm{pH}$ decline to maintain an acceptable quality of beef. This acceptable window is described as the muscle temperature staying above $35^{\circ} \mathrm{C}$ when the $\mathrm{pH}$ is above 6 and the muscle temperature staying below $12^{\circ} \mathrm{C}$ when the $\mathrm{pH}$ is below 6 (Thompson, 2002).

However, there has been little research evaluating how hot carcass weights may influence the rate of muscle temperature and $\mathrm{pH}$ decline and how they may relate to ultimate meat quality attributes of beef steaks. The objectives of this research were to evaluate chilling rate and $\mathrm{pH}$ decline of carcasses from different weights classes and how they relate to meat quality characteristics of longissimus thoracis and semimembranosus steaks.

\section{Materials and Methods}

\section{Experimental design and carcass measurements}

Beef carcasses $(N=59$; light $[n=20]$, medium $[n=19]$, and heavy $[n=20])$ were selected over 5 different collection days over 5 mo at a commercial abattoir (DemKota Ranch Beef, Aberdeen, SD). Carcasses were selected after slaughter and before entering chill coolers. Carcasses that exhibited dairy carcass conformation were excluded from selection. Carcasses were selected in the following weight ranges: light $(<363 \mathrm{~kg})$, medium (363-408 kg), and heavy (>408 kg). Approximately
45 min following exsanguination, carcasses were moved into chill coolers, and muscle $\mathrm{pH}$ was immediately measured using a $\mathrm{pH}$ meter with a solid glass probe (MPI $\mathrm{pH}$ meter, Meat Probes Inc., Topeka, KS) from the center of the semimembranosus and the longissimus thoracis between the 12th and 13th rib. Additionally, temperature was taken and recorded for $24 \mathrm{~h}$ with a multilogger thermometer (HH506RA thermometer, Omega Engineering Inc., Stamford, CT). A thermometer probe (ChromegaAlomega KHSS-18G-RSC12, Omega Engineering Inc.) was inserted into the direct center of the longissimus thoracis muscle on the external fat side at approximately the sixth rib, and a second thermometer probe was inserted directly into the center of semimembranosus muscle. Muscle $\mathrm{pH}$ measurements were taken in the same location at 4 and $24 \mathrm{~h}$ after initial measurements. Average chill cooler temperature was $36^{\circ} \mathrm{C}$ with humidity and air velocity remaining constant over collection days.

After carcasses were chilled for approximately 24 $\mathrm{h}$, the following carcass data were collected: ribeye area; 12th rib backfat; kidney, pelvic, and heart fat $(\mathrm{KPH})$ percentage; marbling score; and USDA final yield grade. USDA final yield grade was calculated using the following equation: yield grade $=2.5+$ $(2.5 \times$ adjusted fat thickness $)+(0.2 \times \mathrm{KPH}$ percentage $)+(0.0038 \times$ hot carcass weight $)-(0.32 \times$ ribeye area) (USDA, 2017). Four carcasses with abnormally dark-colored lean were identified from the selected carcasses and left in the dataset because they represented a real sampling of carcasses in a commercial operation. Ribs and rounds were marked using blue edible grader ink on the external fat surface of the left side to identify primals to specific carcasses. Upon fabrication, ribeye rolls (Institutional Meat Purchase Specification 112A) and inside rounds (Institutional Meat Purchase Specification 160A) were transferred in coolers to the North Dakota State University Meat Laboratory in vacuum-sealed bags and stored in a $4^{\circ} \mathrm{C}$ cooler for aging.

After subprimals were aged for $14 \mathrm{~d}, 3$ test steaks were fabricated from each ribeye roll, and 2 tests steaks were fabricated from each inside round. Ribeye steaks were removed from the caudal end of the ribeye roll with one $\sim 1.2-\mathrm{cm}$ face steak that was not utilized for any analysis and three $\sim 2.5$-cm-thick test steaks being fabricated. The first test steak was immediately overwrapped (Reynolds, Louisville, KY) and placed in a $4^{\circ} \mathrm{C}$ cooler for color stability measures. The second test steak was vacuum sealed and frozen at approximately $-18^{\circ} \mathrm{C}$ for later Warner-Bratzler shear force (WBSF) analysis. The third test steak was used to prepare a 
50-g sample for drip-loss analysis. Round test steaks were fabricated from the semimembranosus muscle. The muscle was split in half across the muscle fibers with 2 test steaks being fabricated from the distal end of the muscle. The first test steak was immediately overwrapped and placed in a $4{ }^{\circ} \mathrm{C}$ cooler for color stability measures. The second test steak was vacuum sealed and frozen at approximately $-18^{\circ} \mathrm{C}$ for WBSF analysis. A 50-g sample was taken for drip-loss analysis from the proximal end of the semimembranosus muscle.

\section{Drip-loss analysis}

Muscle samples from the longissimus thoracis and semimembranosus were suspended from a paperclip in a wire closure bag (Whirl-Pak, Madison, WI) to collect drip loss over a 24 -h time period at $4^{\circ} \mathrm{C}$. An approximate 50 -g sample was collected and weighed prior to suspension and then reweighed after $24 \mathrm{~h}$ to determine drip-loss percentage. Drip loss was calculated with the following equation: ([beginning weight - ending weight $] \div$ [beginning weight $] \times 100$ ) .

\section{Meat color}

Steaks for color stability measurements were overwrapped in oxygen-permeable $(1,000$ to $1,050 \mathrm{~mL}$ of $\mathrm{O}_{2} / 645 \mathrm{~cm}^{2}$ during a 24-h period) polyvinyl chloride packaging film and randomly placed on a table in a $4^{\circ} \mathrm{C}$ cooler under continuous fluorescent lighting (American Fluorescent, model no. PPS232RC, Waukegan, IL). Two $L^{*}, a^{*}$, and $b^{*}$ measurements were taken side by side through the film on the lightexposed surface every $24 \mathrm{~h}$ for $10 \mathrm{~d}$ on a portion of each steak free of subcutaneous fat. A Minolta colorimeter (CR-310 Chromameter, Konica Minolta, Tokyo, Japan) with an aperture size of $55 \mathrm{~mm}$ and a $2^{\circ}$ observer using illuminant D65 (American Meat Science Association, 2012) was used for color collection. Rib and round steaks were randomly moved on the table each day after measurements were taken.

\section{Warner-Bratzler shear force and cook loss analysis}

Steaks for WBSF were thawed overnight for approximately $12 \mathrm{~h}$ and were then allowed to equilibrate to approximately room temperature prior to cooking. Steaks were weighed, and a thermocouple (Omega Engineering Inc., Stamford, CT) was inserted in the geometric center of the steak. Steaks were cooked on clamshell style grills (George Foreman Model No.
GRP99, Columbia, MO) to an internal temperature of $71^{\circ} \mathrm{C}$ and reweighed for cooking loss (American Meat Science Association, 2016). Cook loss was calculated using the follow equation: ([raw weight - cooked weight $] \div$ [raw weight $] \times 100$ ). Steaks were then cooled to room temperature. Six $1.27-\mathrm{cm}$ cores were from the center of the steaks parallel to the muscle fibers. Cores were sheared perpendicular to the muscle fibers using a shear force machine (United-Smart 1 test system SSTM500, United Calibration Corporation, Huntington Beach, CA) with a crosshead speed of $250 \mathrm{~mm} / \mathrm{min}$ with force reported in kilograms. The values were averaged to determine the shear force value for each steak.

\section{Statistical analysis}

Data were analyzed using the PROC MIXED procedure of SAS version 9.4 (SAS Institute, Cary, NC) with weight class as the main effect and carcass as the experimental unit. Collection day was included as a random effect, and means were separated using the PDIFF option and were considered significant when $P \leq 0.05$. Meat color, treatment, day, and treatment $\times$ day were analyzed using the same method, with no significant interaction found between treatment and day, so the interaction was removed.

\section{Results and Discussion}

\section{Temperature decline}

Least-squares means and standard errors for temperature decline for longissimus thoracis muscle and semimembranosus muscle are presented in Table 1. No differences were observed among hot carcass weight groups in longissimus thoracis muscle temperature at $0 \mathrm{~h}(P=0.81)$ and at $24 \mathrm{~h}(P=0.64)$. In addition, no differences were observed among hot carcass weight groups in semimembranosus muscle temperature at $0 \mathrm{~h} \quad(P=0.28)$ and at $4 \mathrm{~h} \quad(P=0.13)$. Longissimus thoracis muscle temperature at $4 \mathrm{~h}$ was lower in carcasses classified as light weight compared with carcasses classified as heavy weight $(P=0.02)$. Additionally, semimembranosus muscle temperature at $24 \mathrm{~h}$ was lower in carcasses classified as light and medium weight compared with carcasses classified as heavy weight $(P<0.0001)$. These differences are in agreement with several papers (Lochner et al., 1979; Jones and Robertson, 1988; Okeudo and Moss, 2005) that observed a difference in muscle temperature decline with increased fat thickness. While 12 th rib fat thickness was not statistically significant 
Table 1. Least-squares means \pm standard errors of the means of the relationship among hot carcass weight and temperature decline in degrees Celsius of beef longissimus thoracis and semimembranosus muscle

\begin{tabular}{|c|c|c|c|c|}
\hline & \multicolumn{3}{|c|}{ Hot Carcass Weights ${ }^{1}$} & \multirow[b]{2}{*}{$P$ value } \\
\hline & Light $(n=20)$ & Medium $(n=19)$ & Heavy $(n=20)$ & \\
\hline \multicolumn{5}{|c|}{ Longissimus thoracis } \\
\hline $0 \mathrm{~h}^{2}$ & $39.62 \pm 0.44$ & $39.57 \pm 0.45$ & $39.47 \pm 0.44$ & 0.81 \\
\hline $4 \mathrm{~h}$ & $23.29 \pm 2.06^{\mathrm{a}}$ & $24.24 \pm 2.08^{\mathrm{ab}}$ & $25.99 \pm 2.08^{\mathrm{b}}$ & 0.02 \\
\hline $24 \mathrm{~h}$ & $9.07 \pm 6.86$ & $9.44 \pm 6.86$ & $9.53 \pm 6.86$ & 0.64 \\
\hline \multicolumn{5}{|c|}{ Semimembranosus } \\
\hline $0 \mathrm{~h}^{2}$ & $39.59 \pm 0.53$ & $40.06 \pm 0.51$ & $40.03 \pm 0.51$ & 0.28 \\
\hline $4 \mathrm{~h}$ & $31.82 \pm 3.38$ & $33.09 \pm 3.34$ & $34.04 \pm 3.31$ & 0.13 \\
\hline $24 \mathrm{~h}$ & $14.67 \pm 9.05^{\mathrm{a}}$ & $15.57 \pm 9.05^{\mathrm{a}}$ & $17.83 \pm 9.04^{\mathrm{b}}$ & $<0.0001$ \\
\hline
\end{tabular}

$(P=0.12)$, there were observed differences in fat thickness between light- and heavy-weight carcasses. It has also been hypothesized that the semimembranosus muscle temperature may be more heavily influenced by spray chilling systems due to the close proximity of the water source to the muscle, as well as having less fat cover over the muscle (Jones and Robertson, 1988).

\section{Muscle $p H$ decline}

Least-squares means and standard errors for $\mathrm{pH}$ decline for longissimus thoracis muscle and semimembranosus muscle are presented in Table 2. No differences among hot carcass weight groups were observed for longissimus thoracis nor semimembranosus muscle $\mathrm{pH}$ at $0 \mathrm{~h}(P \geq 0.46), 4 \mathrm{~h}(P \geq 0.30)$, and 24 $\mathrm{h}(P \geq 0.16)$. These results were expected as glycogen levels would not be different based on hot carcass weight and therefore would not affect muscle $\mathrm{pH}$ decline (Pethick et al., 1995). However, the rate of muscle $\mathrm{pH}$ decline would almost certainly have been affected if a difference in muscle temperature decline had been observed. There are 2 schools of thought about how muscle temperature and $\mathrm{pH}$ decline relate to final meat quality. The first is that $\mathrm{pH}$ of muscle of must fall to 5.6-5.8 when the muscle temperature reaches $7^{\circ} \mathrm{C}$ (Hannula and Puolanne, 2004). The second is that there is a window of acceptability for temperature and $\mathrm{pH}$ decline, wherein the $\mathrm{pH}$ should stay at about 6 when the temperature is above $35^{\circ} \mathrm{C}$ and the $\mathrm{pH}$ should be below 6 when the temperature is below $12^{\circ} \mathrm{C}$ (Thompson, 2002). Interestingly, our data do not fit either of these scenarios, yet we saw no deleterious effects on meat quality attributes. This finding may be explained by the theory that meat quality attributes are most affected when there is a rapid decline in $\mathrm{pH}$ (Hopkins et al., 2014). Of note, the $\mathrm{pH}$ values of the longissimus thoracis muscle were lower in the $4-\mathrm{h}$ period compared with the 24 -h period, which could be attributed to how $\mathrm{pH}$ measurements were taken

Table 2. Least-squares means \pm standard error of means of the relationship among hot carcass weight and $\mathrm{pH}$ decline of beef longissimus and semimembranosus muscle

\begin{tabular}{lccc}
\hline \hline & \multicolumn{3}{c}{ Hot Carcass Weights ${ }^{1}$} \\
\cline { 2 - 4 } & Light $(n=20)$ & Medium $(n=19)$ & Heavy $(n=20)$ \\
\hline Longissimus & & & \\
$0 \mathrm{~h}^{2}$ & $6.48 \pm 0.08$ & $6.49 \pm 0.08$ & $6.54 \pm 0.08$ \\
$4 \mathrm{~h}$ & $5.85 \pm 0.08$ & $5.94 \pm 0.08$ & $5.88 \pm 0.08$ \\
$24 \mathrm{~h}$ & $6.04 \pm 0.05$ & $6.07 \pm 0.05$ & $5.97 \pm 0.05$ \\
Semimembranosus & & & 0.63 \\
$0 \mathrm{~h}$ & $6.48 \pm 0.10$ & $6.39 \pm 0.10$ & 0.30 \\
$4 \mathrm{~h}$ & $5.76 \pm 0.07$ & $5.77 \pm 0.08$ & $5.51 \pm 0.10$ \\
$24 \mathrm{~h}$ & $5.52 \pm 0.02$ & $5.54 \pm 0.02$ & $5.81 \pm 0.07$ \\
\hline
\end{tabular}

${ }^{1}$ Light $<363 \mathrm{~kg}$, medium $363-408 \mathrm{~kg}$, heavy $>408 \mathrm{~kg}$.

${ }^{2} 0 \mathrm{~h}$ is approximately $45 \mathrm{~min}$ after exsanguination. 
(same location repeatedly). When this type of measurement is used, muscle that is in still in the pre-rigor phase can have its $\mathrm{pH}$ altered due to trauma to the cells, which could explain the inconsistency in the measurements (Dutson, 1983).

\section{Carcass characteristics}

Least-squares means and standard errors for carcass characteristics are presented in Table 3. No differences were observed among hot carcass weight groups for fat thickness $(P=0.12), \mathrm{KPH}$ percentage $(P=0.99)$, and marbling score $(P=0.88)$. Hot carcass weight was different across the 3 treatments $(P<$ 0.0001), due to experimental design. Longissimus area was significantly smaller for carcasses from light- and medium-weight groups compared with carcasses classified as heavy weight $(P=0.0002)$. In addition, USDA final yield grade differed between carcasses classified as light weight having lower USDA yield grades compared with carcasses classified as heavy weight $(P=0.04)$. These results were expected due to the known relationship between increasing hot carcass weight and larger longissimus areas and higher USDA final yield grades (Nour et al., 1983).

\section{Drip loss, tenderness, and cook loss}

Least-squares means and standard errors for drip loss, WBSF, and cook loss for steaks from longissimus thoracis muscle and semimembranosus muscle are presented in Table 4. No differences were observed in drip loss $(P \geq 0.15)$, WBSF $(P \geq 0.10)$, and cook loss $(P \geq$ 0.34 ) of longissimus thoracis nor semimembranosus muscle among hot carcass weight groups. These results are likely explained by the fact that we did not see differences in the muscle temperature and $\mathrm{pH}$ decline. However, what is not fully explained is why we did not see any deleterious effects on meat quality since our muscle temperature and $\mathrm{pH}$ decline rates do not match the normal windows for acceptable quality (Thompson, 2002; Hannula and Puolanne, 2004). As previously stated, our results may be explained by findings that would indicate that rapid $\mathrm{pH}$ decline has more effect on final meat quality traits than an acceptable window (Hopkins et al., 2014).

\section{Meat color}

Least-squares means and standard errors for $L^{*}$, $a^{*}$, and $b^{*}$ values of steaks from longissimus thoracis muscle and semimembranosus muscle averaged over $10 \mathrm{~d}$ are presented in Table 5. Because changes in objective meat color over time are well documented, we did not include display day in tabular form. Day of display did not affect longissimus thoracis steak $L^{*}$ values $(P=0.82)$ or semimembranosus steak $L^{*}$ values $(P=0.36)$. Longissimus thoracis steak $L^{*}$ values did differ among carcass weight group $(P<$ 0.0001 ), with steaks from the light-weight group having lower $L^{*}$ values than those from the medium- and heavy-weight groups. In addition, semimembranosus steak $L^{*}$ values also differed among treatments $(P<$ $0.0001)$, with steaks from the light-weight group having lower $L^{*}$ values than those from the medium- and heavy-weight groups. However, these differences are likely due to the inclusion of steaks in the analysis that were evaluated as having darker than normal lean color at the time of grading, with 3 dark-cutting steaks in the light-weight group. This likely led to lower $L^{*}$ values in the light-weight group.

Table 3. Least-squares means of the relationship among hot carcass weight and beef carcass characteristics

\begin{tabular}{|c|c|c|c|c|c|}
\hline & \multicolumn{3}{|c|}{ Hot Carcass Weights $^{1}$} & \multirow[b]{2}{*}{ SEM $^{2}$} & \multirow[b]{2}{*}{$P$ value } \\
\hline & Light $(n=20)$ & Medium $(n=19)$ & Heavy $(n=20)$ & & \\
\hline HCW, kg & $337^{\mathrm{a}}$ & $385^{\mathrm{b}}$ & $450^{\mathrm{c}}$ & 3.8 & $<0.0001$ \\
\hline 12th rib fat thickness, cm & 1.2 & 1.3 & 1.6 & 0.1 & 0.12 \\
\hline Longissimus area, $\mathbf{c m}^{2}$ & $78.5^{\mathrm{a}}$ & $83.0^{\mathrm{a}}$ & $91.1^{\mathrm{b}}$ & 2.6 & 0.0002 \\
\hline КРН, \% & 2.3 & 2.3 & 2.3 & 0.2 & 0.99 \\
\hline USDA final yield grade ${ }^{3}$ & $3.1^{\mathrm{a}}$ & $3.4^{\mathrm{ab}}$ & $3.7^{\mathrm{b}}$ & 0.3 & 0.04 \\
\hline Marbling score ${ }^{4}$ & 452 & 458 & 462 & 18.8 & 0.88 \\
\hline \multicolumn{6}{|c|}{${ }^{1}$ Light $<363 \mathrm{~kg}$, medium $363-408 \mathrm{~kg}$, heavy $>408 \mathrm{~kg}$. } \\
\hline \multicolumn{6}{|c|}{${ }^{2}$ Pooled standard errors of the means (SEM). } \\
\hline \multicolumn{6}{|c|}{$\begin{array}{l}{ }^{3} \mathrm{USDA} \text { yield grade determined as } 2.5+(2.5 \times 12 \text { th rib fat thickness, inches }) \times(0.2 \times \mathrm{KPH} \text {, percentage })+(0.0038 \times \mathrm{HCW} \text {, pounds })-(0.32 \times \text { longissimus } \\
\text { muscle area, square inches }) .\end{array}$} \\
\hline \multicolumn{6}{|l|}{${ }^{4}$ Small $=400$, Modest $=500$} \\
\hline${ }^{\mathrm{a}-\mathrm{c}}$ Means with similar sup & thin rows are $\mathrm{n}$ & tly different $(P>0$ & & & \\
\hline $\mathrm{ICW}$, hot carcass & & & & & \\
\hline
\end{tabular}


Table 4. Least-squares means \pm standard errors of the means of the relationship among hot carcass weight and drip loss, cook loss, and shear force values of beef longissimus and semimembranosus steaks

\begin{tabular}{|c|c|c|c|c|}
\hline & \multicolumn{3}{|c|}{ Hot Carcass Weights ${ }^{1}$} & \multirow[b]{2}{*}{$P$ value } \\
\hline & Light & Medium & Heavy & \\
\hline \multicolumn{5}{|l|}{ Longissimus } \\
\hline$n$ & 19 & 19 & 18 & \\
\hline Drip loss ${ }^{2}, \%$ & $0.80 \pm 0.10$ & $1.00 \pm 0.10$ & $0.70 \pm 0.10$ & 0.20 \\
\hline Cook loss ${ }^{3}, \%$ & $14.64 \pm 1.08$ & $15.07 \pm 1.08$ & $14.66 \pm 1.08$ & 0.95 \\
\hline WBSF, $\mathrm{kg}$ & $2.18 \pm 0.13$ & $2.19 \pm 0.13$ & $2.22 \pm 0.14$ & 0.97 \\
\hline \multicolumn{5}{|c|}{ Semimembranosus } \\
\hline$n$ & 19 & 19 & 19 & \\
\hline Drip loss, $\%$ & $1.00 \pm 0.20$ & $1.00 \pm 0.20$ & $0.70 \pm 0.20$ & 0.15 \\
\hline Cook loss, $\%$ & $24.95 \pm 1.49$ & $26.62 \pm 1.49$ & $24.56 \pm 1.47$ & 0.34 \\
\hline WBSF, $\mathrm{kg}$ & $4.27 \pm 0.22$ & $3.83 \pm 0.22$ & $3.73 \pm 0.22$ & 0.10 \\
\hline
\end{tabular}

Table 5. Least-squares means \pm standard errors of the means of the relationship among hot carcass weight and instrumental color scores averaged over $10 \mathrm{~d}$ of beef longissimus and semimembranosus steaks

\begin{tabular}{|c|c|c|c|c|}
\hline & \multicolumn{3}{|c|}{ Hot Carcass Weights 1} & \multirow[b]{2}{*}{$P$ value } \\
\hline & Light & Medium & Heavy & \\
\hline \multicolumn{5}{|c|}{ Longissimus } \\
\hline$n$ & 19 & 19 & 18 & \\
\hline$L^{*}$ & $45.94 \pm 0.26^{\mathrm{a}}$ & $48.41 \pm 0.26^{\mathrm{b}}$ & $48.11 \pm 0.26^{\mathrm{b}}$ & $<0.0001$ \\
\hline$a^{*}$ & $22.59 \pm 0.25^{\mathrm{a}}$ & $22.16 \pm 0.25^{\mathrm{a}}$ & $23.55 \pm 0.25^{\mathrm{b}}$ & 0.0003 \\
\hline$b^{*}$ & $10.51 \pm 0.14^{\mathrm{a}}$ & $10.69 \pm 0.14^{\mathrm{a}}$ & $11.35 \pm 0.14^{\mathrm{b}}$ & $<0.0001$ \\
\hline \multicolumn{5}{|c|}{ Semimembranosus } \\
\hline$n$ & 19 & 19 & 19 & \\
\hline$L^{*}$ & $43.83 \pm 0.23^{\mathrm{a}}$ & $46.94 \pm 0.23^{b}$ & $46.88 \pm 0.22^{\mathrm{b}}$ & $<0.0001$ \\
\hline$a^{*}$ & $20.39 \pm 0.28^{\mathrm{a}}$ & $21.30 \pm 0.28^{\mathrm{b}}$ & $21.35 \pm 0.27^{\mathrm{b}}$ & 0.02 \\
\hline$b^{*}$ & $10.08 \pm 0.13^{\mathrm{a}}$ & $11.30 \pm 0.13^{b}$ & $11.28 \pm 0.12^{\mathrm{b}}$ & $<0.0001$ \\
\hline
\end{tabular}

${ }^{1}$ Light $<363 \mathrm{~kg}$, medium $363-408 \mathrm{~kg}$, heavy $>408 \mathrm{~kg}$.

${ }^{\mathrm{a}, \mathrm{b}}$ Means with similar superscripts within rows are not significantly different $(P>0.05)$.

Display day significantly affected longissimus thoracis steak $(P<0.0001)$ and semimembranosus steak $a^{*}$ values $(P<0.0001)$ (data not shown). Display day differences in $a^{*}$ were expected as it is well known that steaks begin to lose redness as the days of display increase (McKenna et al., 2005). More importantly, carcass weight groups affected longissimus thoracis steak $(P=0.0003)$ and semimembranosus steak $a^{*}$ values $(P=0.022)$. Longissimus thoracis and semimembranosus steaks from carcasses classified as light weight had lower $a^{*}$ values compared with $a^{*}$ values of longissimus thoracis and semimembranosus steaks from carcasses classified as medium and heavy weight. Page et al. (2001) also reported weak, but significant, correlations among hot carcass weight and $a^{*}$ values in which carcass weight showed a weak and positive correlation with $a^{*}$, which is similar to what we observed.

Display day significantly affected $b^{*}$ values for longissimus thoracis steak $(P<0.0001)$ and semimembranosus steaks $(P<0.0001)$ (data not shown). Additionally, carcass weight groups were different for longissimus thoracis steak $b^{*}$ values $(P<0.0001)$ and semimembranosus steak $b^{*}$ values $(P<0.0001)$. Longissimus thoracis steak and semimembranosus steak from carcasses classified as light weight had lower $b^{*}$ values compared with steaks from carcasses classified as medium and heavy weight. Page et al. (2001) also reported weak, but significant, positive correlations among hot carcass weight and $b^{*}$ values, but with a much larger sample size. 


\section{Conclusions}

Our results indicate that there is some influence on muscle temperature decline owing to hot carcass weight. Additionally, our results were in agreement with literature demonstrating that carcass weights influence longissimus size and final USDA yield grade (Nour et al., 1983). Furthermore, our results indicated that muscle $\mathrm{pH}$ values may have some influence on meat color, especially $a^{*}$ and $b^{*}$ values. Of particular interest is that the steaks from the longissimus muscle and semimembranosus muscle from medium-weight and heavy-weight carcasses had higher $a^{*}$ values, which suggests that steaks from medium- and heavyweight carcasses may have an advantage in stabilizing a more desirable cherry-red color that most consumers prefer (Kropf, 1980; Holman et al., 2017). However, our results did not indicate that hot carcass weight had any influence on WBSF or cooking or drip loss of longissimus or semimembranosus steaks.

\section{Acknowledgments}

Funding for this study was provided in part by the North Dakota Beef Commission using Beef Checkoff funds.

\section{Literature Cited}

American Meat Science Association. 2012. Meat color measurement guidelines. 2nd ed. Am. Meat Sci. Assoc., Champaign, IL.

American Meat Science Association. 2016. Research guidelines for cookery, sensory evaluation, and instrumental tenderness measurements of meat. 2nd ed. Am. Meat Sci. Assoc., Champaign, IL.

Boleman, S. J., S. L. Boleman, R. K. Miller, J. F. Taylor, H. R. Cross, T. L. Wheeler, M. Koohmaraie, S. D. Shackleford, M. F. Miller, R. L. West, D. D. Johnson, and J. W. Savell. 1997. Consumer evaluation of beef of known categories of tenderness. J. Anim. Sci. 75:1521-1524. https://doi.org/10. 2527/1997.7561521x.

Dutson, T. R. 1983. The measurement of $\mathrm{pH}$ in muscle and its importance to meat quality. 36th Recip. Meat Conf. Proc., Fargo, North Dakota. p. 92-97.

Hannula, T., and E. Puolanne. 2004. The effect of cooling rate on beef tenderness: The significance of $\mathrm{pH}$ at $7^{\circ} \mathrm{C}$. Meat Sci. 67:403-408. https://doi.org/10.1016/j.meatsci.2003.11.012.

Holman, B. W. B., R. J. Van de Ven, Y. Mao, C. E. O. Coombs, and D. L. Hopkins. 2017. Using instrumental (CIE and reflectance) measures to predict consumers' acceptance of beef color. Meat Sci. 127:57-62. https://doi.org/10.1016/j. meatsci.2017.01.005.
Hopkins, D. L., E. N. Ponnampalam, R. J. van de Ven, and R. D. Warner. 2014. The effect of $\mathrm{pH}$ decline rate on the meat and eating quality of beef carcasses. Anim. Prod. Sci. 52:407-413. https://doi.org/10.1071/AN12314.

Igo, J. L., D. L. VanOverbeke, D. R. Woerner, J. D. Tatum, D. L. Pendell, L. L. Vedral, G. G. Mafi, M. C. Moore, R. O. McKeith, G. D. Gray, D. B. Griffin, D. S. Hale, J. W. Savell, and K. E. Belk. 2013. Phase I of The National Beef Quality Audit-2011: Quantifying willingness-to-pay, bestworst scaling, and current status of quality characteristics in different beef industry marketing sectors. J. Anim. Sci. 91:1907-1919. https://doi.org/10.2527/jas.2012-5815.

Jones, S. D. M., and W. M. Robertson. 1988. The effects of spraychilling carcasses on the shrinkage and quality of beef. Meat Sci. 24:177-188. https://doi.org/10.1016/0309-1740(88) 90076-9.

Kropf, D. H. 1980. Effects of retail display conditions on meat color. 41st Recip. Meat Conf. Proc., West Lafayette, IN.

Lochner, J. V., R. G. Kauffman, and B. B. Marsh. 1979. Early postmortem cooling rate and beef tenderness. Meat Sci. 4:227241. https://doi.org/10.1016/0309-1740(80)90051-0.

Locker, R. H., and C. J. Hagyard. 1963. A cold shortening effect in beef muscles. J. Sci. Food. Agr. 14:787-793. https://doi.org/ 10.1002/jsfa.2740141103.

Maples, J. G., J. L. Lusk, and D. S. Peel. 2018. Unintended consequences of the quest for increased efficiency in beef cattle: When bigger isn't better. Food Policy. 74:65-73. https:// doi.org/10.1016/j.foodpol.2017.11.005.

McKenna, D. R., P. D. Mies, B. E. Baird, K. D. Pfeiffer, J. W. Ellebracht, and J. W. Savell. 2005. Biochemical and physical factors affecting discoloration characteristics of 19 bovine muscles. Meat Sci. 70:665-682. https://doi.org/10.1016/j. meatsci.2005.02.016.

NBQA. 2016. National Beef Quality Audit Executive Summary. National Cattleman's Beef Association. https://www.bqa. org/resources/national-beef-quality-audits/2016-nationalbeef-quality-audit. (Accessed 17 July 2018).

Nour, A. Y. M., M. L. Thonney, J. R. Stouffer, and W. R. C. White. 1983. Changes in carcass weight and characteristics with increasing weight of large and small cattle. J. Anim. Sci. 57:1154-1165. https://doi.org/10.2527/jas1983.5751154x.

Okeudo, N. J., and B. W. Moss. 2005. Interrelationships amongst carcass and meat quality characteristics of sheep. Meat Sci. 69:1-8. https://doi.org/10.1016/j.meatsci.2004.04.011.

Page, J. K., D. M. Wulf, and T. R. Schwotzer. 2001. A survey of beef muscle color and pH. J. Anim. Sci. 79:678-687. https:// doi.org/10.2527/2001.793678x.

Pethick, D. W., J. B. Rowe, and G. Tudor. 1995. Glycogen metabolism and meat quality. Rec. Adv. An. 13:97-103. http:// livestocklibrary.com.au/handle/1234/19784.

Thompson, J. 2002. Managing meat tenderness. Meat Sci. 62:295308. https://doi.org/10.1016/S0309-1740(02)00126-2.

USDA. 2017. United States standards for grades of carcass beef. Livest. Seed Program, Agric. Market. Serv., Washington, DC. 